\title{
Grain Refinement of Tough Pitch Copper by Electromagnetic Vibrations during Solidification
}

\author{
Yoshiki Mizutani ${ }^{1, *}, K_{\text {Kenji Miwa }}^{1}$, Takuya Tamura ${ }^{1}$, Yoshihiro Nakai ${ }^{2}$ and Yasuyuki Otsuka ${ }^{2}$ \\ ${ }^{1}$ Materials Research Institute for Sustainable Development, National Institute of Advanced Industrial Science \\ and Technology (AIST), Nagoya 463-8560, Japan \\ ${ }^{2}$ Sumitomo Electric Industries, LTD., Osaka 554-0024, Japan
}

\begin{abstract}
Electromagnetic vibrations, which are generated by simultaneous imposition of a static magnetic field and an alternating electric field, were applied to the refinement of crystal grains of tough pitch copper. The electromagnetic vibrations of the frequency range from $100 \mathrm{~Hz}$ to $10 \mathrm{kHz}$ were imposed during solidification of the copper rod. Within this frequency range, the vibration frequency of about $100 \mathrm{~Hz}$ was found to be the most effective in refining the copper crystal grains and the average grain size was refined up to $200 \mu \mathrm{m}$, which otherwise was around $600 \mu \mathrm{m}$ in a nonvibrated specimen. It was concluded that by the electromagnetic vibration process tough pitch copper could also be refined as well as Al-Si alloys and AZ91D alloys. [doi:10.2320/matertrans.47.1793]
\end{abstract}

(Received February 23, 2006; Accepted May 11, 2006; Published July 15, 2006)

Keywords: electromagnetic vibrations, grain refinement, pure copper, vibration frequency

\section{Introduction}

In order to build a sustainable society, good recycling efficiency and the reduction of the weight are desired for many products such as cars or electric products. In many of these products, copper wire is widely used as a conductor. To reduce the diameter of the copper wire is considered as an easy to get lighter products. However, a problem arises in that the mechanical strength declines with decrease of wire diameter. Regarding the mechanical properties, the HallPetch relation ${ }^{1,2)}$ shows that the yield stress is proportional to the inverse square root of the average grain diameter. To date, many studies ${ }^{3-11)}$ on addition of other elements have been carried out to achieve grain-refined microstructures by doping some elements so that the mechanical properties can be improved. Particularly $\mathrm{Cu}-\mathrm{Ti}$ alloys have extra higher strength than other copper alloys, while the electric conductivity becomes worse with the addition of $\mathrm{Ti}^{7-10)}$ In the meanwhile, the addition of other elements makes the recycling efficiency worse as well. Therefore, a grain refinement method of pure copper without doping any other elements is desired for improved mechanical properties.

The rapid cooling ${ }^{12-15)}$ method and the application of ultrasonic wave vibration ${ }^{16-20)}$ are considered as two effective alternatives to obtain fined microstructures, without adding other elements. By using the former method, very fine microstructures on the micro- and nanoscales, or amorphous phase can be achieved in thin ribbons or atomized powders due to the necessity of achieving enormously high cooling rate. By using the latter method, the microstructure of a bulk sample can be refined and also has other effects, such as the uniform dispersion of inclusion materials and degassing. However, this method has also serious problems such as the dissolution of a transmitter when it is applied at high temperatures, and attenuation of vibrations in the regions remote from the vibrator.

*Present address: Machine and Metal Division, Industrial Technology Center Gifu Prefecture Government, Seki 501-3265, Japan
When the alternating current is passed through a molten metal perpendicular to the static magnetic field, the molten metal is alternately subjected to the Lorentz force and so vibrated directly at the same frequency as the alternating current. Simultaneous imposition of a magnetic field and an alternating electric field is able to generate vibrations of a molten metal. This method is free from the problem occurring in ultrasonic wave vibrations, and thus it is a promising process. Recently, several studies on structural refinement have been carried out ${ }^{21-31)}$ by using this vibration method. The vibrations lead to the cavitation phenomenon, which is burst phenomenon of cavities generated by the vibrations. When the cavities burst, enormous energy is released and can inflict extensive damage to the solid wall as erosion or collapse. Miwa termed this cavitation phenomenon "micro-explosion" phenomenon. ${ }^{28)}$ Thus, the electromagnetic vibration technique is able to refine the microstructure without any refiners, and thus it is very useful for creation of a sustainable society with a low impact on the environment.

In this paper, the electromagnetic vibration process was applied to the structural refinement of tough pitch copper (TPC), kind of pure copper. In the meanwhile, the effect of the electromagnetic vibration on the solidified structure is investigated in terms of the vibration frequency.

\section{Experiments}

Schematic diagram of experimental apparatus was shown in Fig. 1. Dimension of the tough pitch copper specimen was $5.8 \mathrm{~mm}$ in diameter and $70 \mathrm{~mm}$ in length. The purity of this TPC specimen was substantially high, as shown in Table 1. Carbon electrodes $(6 \mathrm{~mm}$ in diameter and $15 \mathrm{~mm}$ in length) were attached at both sides of the TPC specimen and encapsulated in $\mathrm{Si}_{3} \mathrm{~N}_{4}$ tube $(15 \mathrm{~mm}$ in outer diameter, $6 \mathrm{~mm}$ in inner diameter and $100 \mathrm{~mm}$ in length), as shown in Fig. 2. A thermocouple was inserted at the bottom of the specimen through a hole in the wall of $\mathrm{Si}_{3} \mathrm{~N}_{4}$ tube.

The $\mathrm{Si}_{3} \mathrm{~N}_{4}$ tube with the TPC specimen was inserted in the 


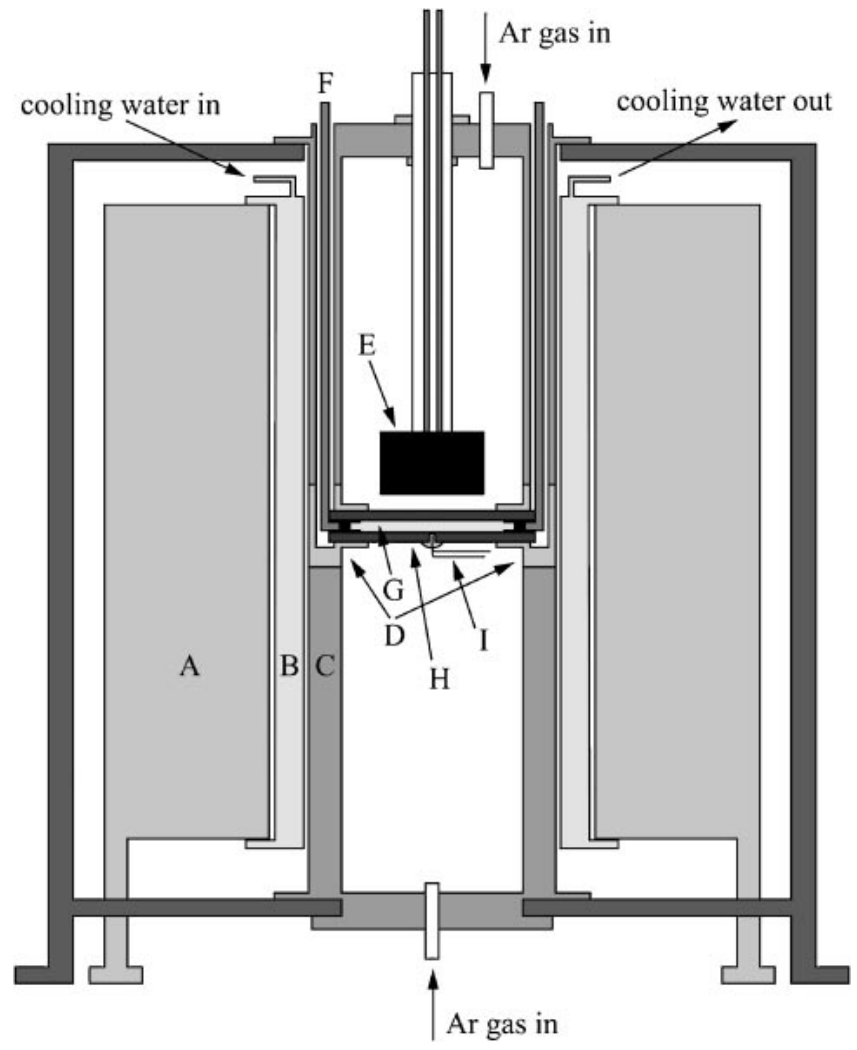

Fig. 1 Cross sectional view of the experimental apparatus. (A) superconducting magnet, (B) cooling jacket, (C) stainless steel cylinders, (D) specimen holding assembly, (E) electric heating furnace, $(\mathrm{F})$ copper electrode rod, (G) specimen, $(\mathrm{H}) \mathrm{Si}_{3} \mathrm{~N}_{4}$ tube, (I) thermocouple.

Table 1 Chemical composition of tough pitch copper.

\begin{tabular}{ccccccc}
\hline $\mathrm{Ag}$ & $\mathrm{Sn}$ & $\mathrm{S}$ & $\mathrm{Fe}$ & $\mathrm{O}$ & Other & $\mathrm{Cu}$ \\
\hline 12 & 7 & 3 & 2 & 223 & $<1$ & remains \\
\hline
\end{tabular}

(The unit of all columns is ppm.)

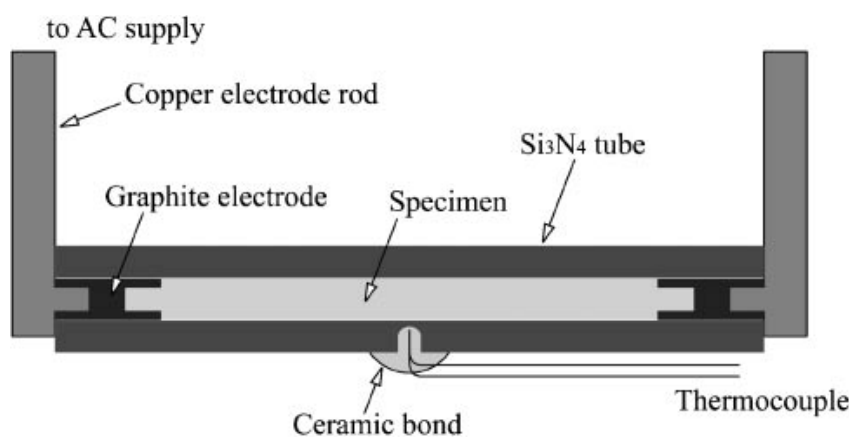

Fig. 2 Schematic illustration of configuration of specimen and electrodes in $\mathrm{Si}_{3} \mathrm{~N}_{4}$ tube.

bore of superconducting magnet, which is able to generate a magnetic-flux density of up to 10 Tesla (T) at the center of a bore in $150 \mathrm{~mm}$ diameter, and firmly fixed by two stainless steel cylinders at the center of magnetic field, as shown in Fig. 1. The TPC specimen was connected for AC power supply. The specimen was heated by an electric heating furnace covering the sample. During cooling the furnace can be removed from sample. Ar gas was flowed into the stainless

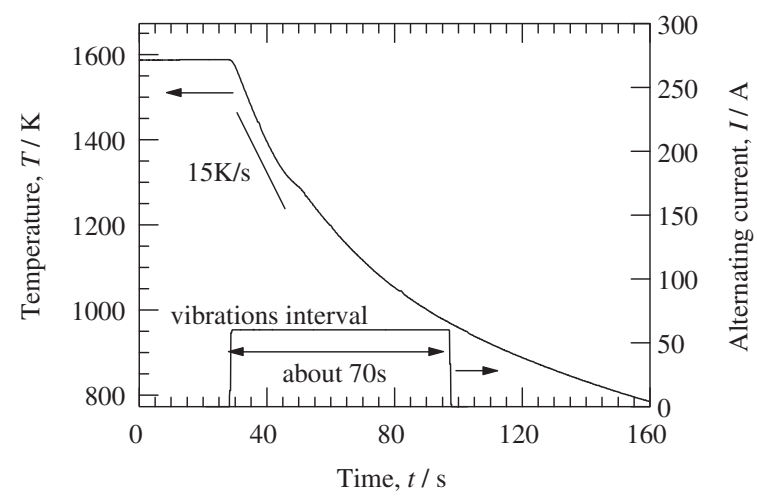

Fig. 3 Cooling curve of vibrated specimen and timing curve of applied alternating current. (magnetic field: $10 \mathrm{~T}$, intensity of electric current: $60 \mathrm{~A}$, frequency of electric current: $500 \mathrm{~Hz}$ ).

steel cylinder to protect the furnace from oxidation.

Experiment of electromagnetic vibration was carried out as following procedures. After a magnetic flux density reached $10 \mathrm{~T}$, the TPC specimen encapsulated in the $\mathrm{Si}_{3} \mathrm{~N}_{4}$ tube was heated by the electric furnace up to about $1573 \mathrm{~K}$ and kept for $120 \mathrm{~s}$. Then the electric furnace was removed above and alternating current with a frequency range from $100 \mathrm{~Hz}$ to $10 \mathrm{kHz}$ and the intensity of $60 \mathrm{~A}$ was passed through the specimen at the same time. The magnetic field acts on the specimen toward the vertical direction, while alternating current passes along the specimen. As a result, an alternating Lorentz force is generated by the simultaneous imposition of these two fields and the specimen is directly vibrated at the same frequency as the alternating current. The alternating current was on until $973 \mathrm{~K}$ that the specimen could solidify completely. In this experimental method, melted region of the specimen was approximately $50 \mathrm{~mm}$ out of $70 \mathrm{~mm}$ in length. The solidified specimen was cut into five pieces at the cross section perpendicular to the alternating current direction with an interval of approximately $5 \mathrm{~mm}$ from center. Grain size in each cross section was measured and average grain size was estimated from three cross sections that had typical structure in the five cross sections.

The effect of vibration frequency on structural refinement was investigated by changing the frequency of the alternating current in a range from $100 \mathrm{~Hz}$ to $10 \mathrm{kHz}$. For comparison, nonvibrated specimen was also prepared with following experimental condition; magnetic-flux density was $0 \mathrm{~T}$, and the alternating current with the same intensity of $60 \mathrm{~A}$ and frequency of $200 \mathrm{~Hz}$ was passed to prevent cooling rate from changing due to the Joule heat by the passed alternating current. Although the magnetic field generated by the alternating current of $60 \mathrm{~A}$, intensity of the magnetic field was very weak in comparison with the magnetic field by the superconducting magnet. Therefore, the specimen was considered to be nonvibrated.

\section{Results and Discussion}

Figure 3 shows a cooling curve of TPC specimen subjected to the static magnetic field of $10 \mathrm{~T}$ and the alternating current with the intensity of $60 \mathrm{~A}$ and the frequency of $500 \mathrm{~Hz}$. Exothermic heat due to growth of 
(a)

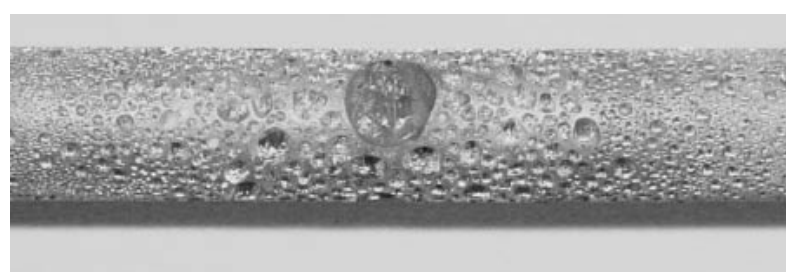

(b)

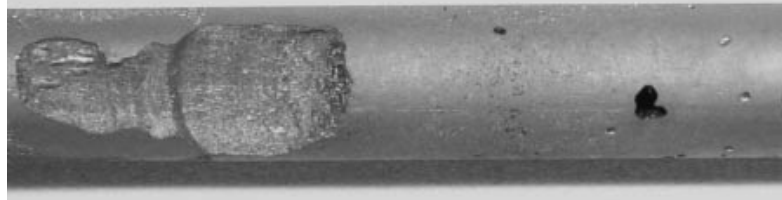

(c)

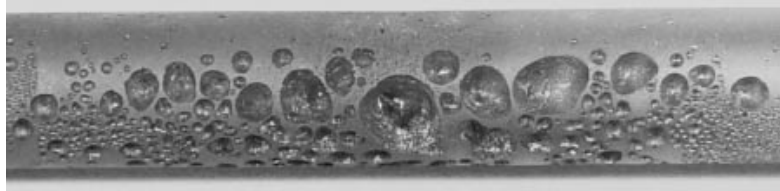

(d)

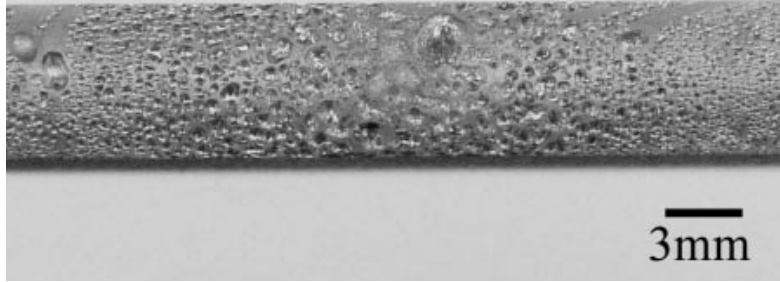

Fig. 4 Appearances of the solidified specimen: (a) nonvibrated specimen $(0 \mathrm{~T}, 60 \mathrm{~A}, 200 \mathrm{~Hz})$, (b)-(d) vibrated specimens $(10 \mathrm{~T}, 60 \mathrm{~A}$ and $\mathrm{AC}$ frequency of (b) $150 \mathrm{~Hz}$, (c) $5 \mathrm{kHz}$, (d) $10 \mathrm{kHz}$ ).

copper crystals was slightly detected at around $1273 \mathrm{~K}$ as shown in the cooling curve of Fig. 3. Cooling rate before the exothermic reaction was about $15 \mathrm{~K} / \mathrm{s}$. The alternating current was stopped at $973 \mathrm{~K}$ which the specimen sufficiently solidified, as shown in Fig. 3. The imposition time of the alternating current was about $70 \mathrm{~s}$ for all specimens. In this period, the specimen was kept to be electromagnetically subjected to the vibration force. Similar cooling curves were detected for the all other specimens regardless of the intensity of static magnetic field or the frequency of alternating current.

Figure 4 depicts the appearances of TPC specimen after the experiment. Figure 4(a) shows an appearance of nonvibrated specimen subjected to the static magnetic field of $0 \mathrm{~T}$ and the alternating current with the intensity of $60 \mathrm{~A}$ and the frequency of $200 \mathrm{~Hz}$, and Figs. 4(b), (c) and (d) show those of vibrated specimens subjected to the static magnetic field of $10 \mathrm{~T}$ and the alternating current with the intensity of $60 \mathrm{~A}$ and the frequencies of $150,5 \mathrm{k}$, and $10 \mathrm{kHz}$, respectively. In the case of the nonvibrated specimen, many small pores existed all over the surface and a large shrinkage existed at the center as shown in Fig. 4(a). These pores indicated that many semispherical bubbles remained on the inner surface of the $\mathrm{Si}_{3} \mathrm{~N}_{4}$ tube. When the electromagnetic vibrations with a frequency of $150 \mathrm{~Hz}$ were imposed on the specimen, few small pores were observed on the surface and only a large shrinkage could be formed, as shown in Fig. 4(b). The specimen vibrated at a rather low frequency, under $1 \mathrm{kHz}$, had the same feature with the specimen shown in Fig. 4(b). In the case of the specimen vibrated at $5 \mathrm{kHz}$, few pores existed at one side of the specimen, and many small pores and several large pores existed at other side, as shown in Fig. 4(c). Small bubbles shown in Fig. 4(a) may migrate along the inner surface of the $\mathrm{Si}_{3} \mathrm{~N}_{4}$ tube by the effect of vibrations and then large bubbles were formed by coalescence of these small bubbles. For the frequency of $5 \mathrm{kHz}$, the small bubbles migrated gradually due to rather small displacement in a half cycle of the vibration, and so long time was necessary for the aggregation of the bubbles. In the case of the low frequencies with large displacement in a half cycle, under $1 \mathrm{kHz}$, the bubbles moved drastically and aggregated in an instant, and the large shrinkage was formed easily as shown in Fig. 4(b). Therefore, a shape of the specimen shown in Fig. 4(c) resulted from solidification in the middle of aggregation and coalescence of bubbles. In the case of the specimen vibrated at $10 \mathrm{kHz}$ shown in Fig. 4(d), many small pores were observed all over the surface just like the nonvibrated specimen shown in Fig. 4(a). The small bubbles could hardly migrate because amplitude of vibrations was too small at the frequency of $10 \mathrm{kHz}$. Consequently, the specimen vibrated at $10 \mathrm{kHz}$ solidified with many small bubbles dispersed all over the surface as shown in Fig. 4(d). Obviously the shape of solidified specimen was dependent on the vibration frequency.

Figure 5 shows typical microstructures of cross section perpendicular to the alternating current. The microstructure shown in Fig. 5(a) is one of nonvibrated specimen subjected to the static magnetic field of $0 \mathrm{~T}$ and the alternating current with the intensity of $60 \mathrm{~A}$ and the frequency of $200 \mathrm{~Hz}$, and Figs. 5(b), (c), (d), (e) and (f) are those of vibrated specimens subjected to the static magnetic field of $10 \mathrm{~T}$ and the alternating current with the intensity of $60 \mathrm{~A}$ and the frequencies of $100,150,500,5 \mathrm{k}$ and $10 \mathrm{kHz}$ respectively. In the nonvibrated specimen shown in Fig. 5(a), the circumference of specimen was rough because of many small pores shown in Fig. 4(a). The microstructure of the nonvibrated specimen consisted of coarse crystal grains and many dendrites were clearly observed like a substructure in the grains. In the specimens vibrated at frequencies of 100, 150 and $500 \mathrm{~Hz}$, as shown in Figs. 5(b), (c) and (d) respectively, these specimens had contact with the $\mathrm{Si}_{3} \mathrm{~N}_{4}$ tube due to the effect of vibrations and thus the remained gas, which existed between the specimen and the $\mathrm{Si}_{3} \mathrm{~N}_{4}$ tube, resulted in pores, as shown in Fig. 4(b). The microstructure of these specimens was refined to many small grains and equiaxed dendritic substructure was observed vaguely in some grains. For the specimen vibrated at $500 \mathrm{~Hz}$, a hybrid microstructure with fine grain and coarse dendrite can be observed, as shown in Fig. 5(d). In the case of the specimen vibrated at $5 \mathrm{kHz}$, several large pores were observed on the surface and crystal grains were rather coarse, as shown in Fig. 5(e). When the frequency of alternating current increased to $10 \mathrm{kHz}$, the macro-morphology of the specimen surface was similar to that of nonvibrated specimen and the microstructure of the specimen consisted coarser crystal grains, as shown in Fig. 5(f).

The average grain size of three cross sections for each specimen was measured from the microstructural images shown in Fig. 5 and the relationship between the average 

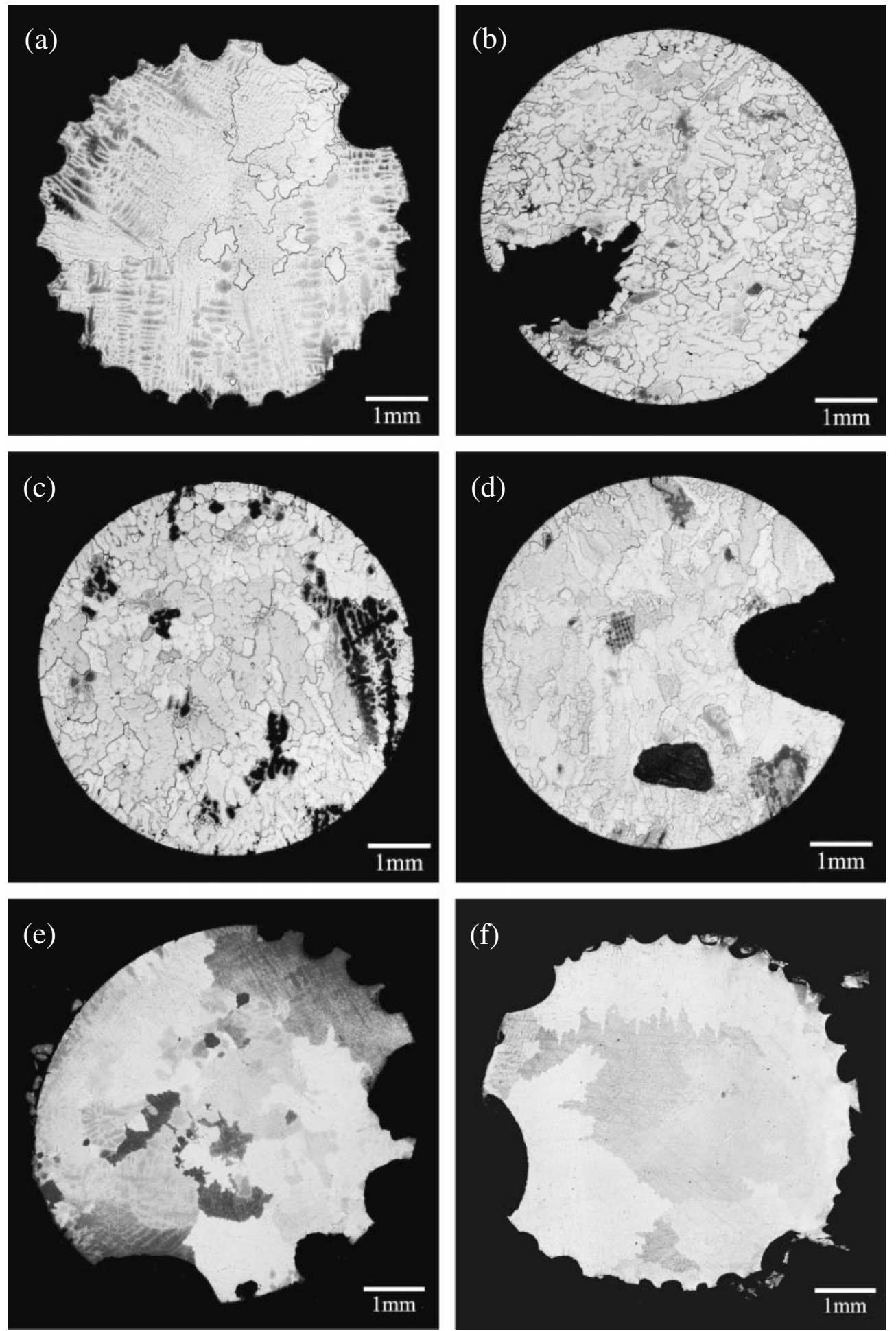

Fig. 5 Solidified microstructures of TPC specimen: (a) nonvibrated specimen (0 T, $60 \mathrm{~A}, 200 \mathrm{~Hz})$, (b)-(f) vibrated specimens (10 T, $60 \mathrm{~A}$ and $\mathrm{AC}$ frequency of (b) $100 \mathrm{~Hz}$, (c) $150 \mathrm{~Hz}$, (d) $500 \mathrm{~Hz}$, (e) $5 \mathrm{kHz}$, (f) $10 \mathrm{kHz}$ ).

grain size and the vibration frequency is shown in Fig. 6. In the case of nonvibrated specimen, the average grain sizes of each cross section were scattering widely and the average grain size was approximately $600 \mu \mathrm{m}$. When the electromagnetic vibrations were imposed to the specimen, the average grain size was less than $200 \mu \mathrm{m}$ and the smallest at the frequency of $100 \mathrm{~Hz}$. In a range of frequency from $1 \mathrm{kHz}$ to $5 \mathrm{kHz}$, crystal grains of TPC became larger and the average grain size was approximately $400 \mu \mathrm{m}$. In the case of the specimen vibrated at $10 \mathrm{kHz}$, the average grain sizes of each cross section scattered widely and the average size was larger than that of the nonvibrated specimen. It makes clear that the electromagnetic vibrations with a too high frequency have little effect on the refinement. This corresponds to the fact that surface of the specimen vibrated at $10 \mathrm{kHz}$ was similar to that of the nonvibrated sample, as shown in Figs. 4(d) and 


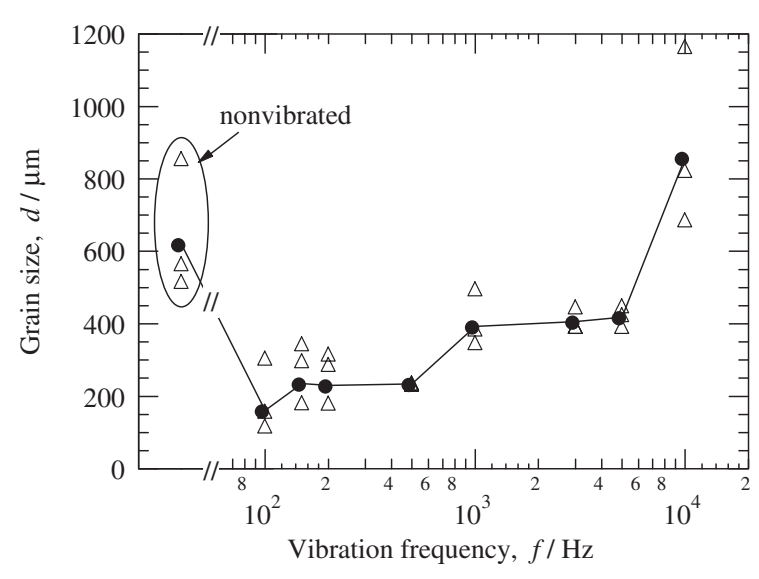

Fig. 6 Effect of vibration frequency on grain size. $\triangle$ : average grain size at cross section, : average grain size.

5(f). To achieve grain-refined microstructure for TPC by the electromagnetic vibrations, a rather low frequency about $100 \mathrm{~Hz}$ was most effective and there was the tendency that the average grain size increased with the increment of vibration frequency.

In the previous results on $\mathrm{Al}-7 \% \mathrm{Si}$ alloy ${ }^{30)}$ and AZ91D magnesium alloy, ${ }^{31)}$ it was considered that primary dendrite arms were fractured by the cavitation phenomenon named micro-explosion, which brings on a burst of cavities generated by the electromagnetic vibrations, and consequently the structural refinement was obtained. In this experimental, the dendritic substructure was observed in crystal grains even in TPC that is a pure copper, as shown in Fig. 5(a). This indicated that dendrites of TPC grew at the early stages of crystal growth. These dendrite arms were fractured by the micro-explosion and consequently the refinement of crystal grains was achieved even in TPC. However, at the high frequency movement of the melt may not reach such higher frequencies of the imposed alternating current, because the period of vibrations is too short. Therefore, it is considered that few cavitation phenomena occur, and thus the primary particles are barely crushed.

\section{Conclusions}

The electromagnetic vibration process was employed for the grain refinement of pure copper (TPC: tough pitch copper). When the alternating current and the static magnetic field of $10 \mathrm{~T}$ were simultaneously imposed to the melt of TPC in the cooling stage, crystal size of grains of TPC decreased without increase of the cooling rate. In a frequency range from $100 \mathrm{~Hz}$ to $10 \mathrm{kHz}$, the most effective frequency band for grain refinement for the metal was 100 to $500 \mathrm{~Hz}$. When the vibration frequency was in a range from 1 to $5 \mathrm{kHz}$, the grain refinement became less effective and consequently the average grain size became coarse with increasing vibration frequency. At the frequency of $10 \mathrm{kHz}$, the microstructure and shape of the specimen were similar to those of non- vibrated specimen. It was apparent that there was little effect on the grain refinement at too high frequencies of electromagnetic vibration.

\section{Acknowledgments}

The authors are grateful to Sumitomo Electric Industries, Ltd. for supplying pure copper. The authors also thank Mr. H. Matsubara and Dr. H. Park for technical assistance, and Dr. M. Li for English grammar.

\section{REFERENCES}

1) E. O. Hall: Proc. Phys. Soc. B64 (1951) 747-753.

2) N. J. Petch: J. Iron Steel Inst. 174 (1953) 25-28.

3) R. G. Fleck, G. J. Cocks and M. R. Taplin: Metall. Trans. 1 (1970) 3415-3420.

4) W. L. Phillips and R. W. Armstrong: Metall. Trans. 3 (1972) 25712577.

5) N. Hansen: Acta Metall. 25 (1977) 863-869.

6) N. Hansen and B. Ralph: Acta Metall. 30 (1982) 411-417.

7) S. Nagarjuna, M. Srinivas, K. Balasubramanian and D. S. Sarma: Scripta Metall. 30 (1994) 1593-1597.

8) S. Nagarjuna, M. Srinivas, K. Balasubramanian and D. S. Sarma: Scripta Metall. Mater. 33 (1995) 1455-1460.

9) S. Nagarjuna, M. Srinivas, K. Balasubramanian and D. S. Sarma: Acta Mater. 44 (1996) 2285-2293.

10) S. Nagarjuna, M. Srinivas, K. Balasubramanian and D. S. Sarma: Mater. Sci. Eng. A259 (1999) 34-42.

11) S. Nagarjuna, M. Srinivas and K. K. Sharma: Acta Mater. 48 (2000) 1807-1813.

12) J. J. Gilman: Phil. Trans. R. Soc. Lond. A322 (1987) 425-438.

13) M. Gremaud, M. Carrard and W. Kurz: Acta Metall. Mater. 39 (1991) 1431-1443.

14) G. A. Bertero, W. H. Hofmeister, M. B. Robinson and R. J. Bayuzick: Metall. Trans. A22 (1991) 2713-2721.

15) J. H. Perepezko, J. L. Sebright, P. G. Höckel and G. Wilde: Mater. Sci. Eng. A326 (2002) 144-153.

16) E. A. Hiedemann: J. Acoust. Soc. America 26 (1954) 831-842.

17) O. V. Abramov: Ultrasonics 25 (1987) 73-82.

18) V. O. Abramov, O. V. Abramov, B. B. Straumal and W. Gust: Mater. Des. 18 (1997) 323-326.

19) N. Enomoto, Y. Iimura and Z. Nakagawa: J. Mater. Res. 12 (1997) 371-376.

20) Y. Osawa, G. Arakane, S. Takamori, A. Sato and O. Ohashi: Journal of Japan Foundry Engineering Society 71 (1999) 98-103.

21) C. Vivès: Mater. Sci. Eng. A173 (1993) 169-172.

22) C. Vivès: Metall. Mater. Trans. B27 (1996) 445-455.

23) C. Vivès: Metall. Mater. Trans. B27 (1996) 457-464.

24) A. Radjai, K. Miwa and T. Nishio: Metall. Mater. Trans. A29 (1998) 1477-1484.

25) A. Radjai and K. Miwa: Metall. Mater. Trans. A31 (2000) 755-762.

26) A. Radjai and K. Miwa: Metall. Mater. Trans. A33 (2002) 3025-3030.

27) S. Kawai, Q. Wang, K. Iwai and S. Asai: Mater. Trans. 42 (2001) 275280.

28) K. Miwa: AIST Today 1 (2001) 15-18.

29) Y. Mizutani, S. Kawai, K. Miwa, K. Yasue, T. Tamura and Y. Sakaguchi: Mater. Trans. 45 (2004) 1939-1943.

30) Y. Mizutani, Y. Ohura, K. Miwa, K. Yasue, T. Tamura and Y. Sakaguchi: Mater. Trans. 45 (2004) 1944-1948.

31) Y. Mizutani, J. Kawata, K. Miwa, K. Yasue, T. Tamura and Y. Sakaguchi: J. Mater. Res. 19 (2004) 2997-3003. 